\title{
Genome-wide detection of copy number variants in European autochthonous and commercial pig breeds by whole-genome sequencing of DNA pools identified breed-characterising copy number states
}

\author{
S. Bovo* (D, A. Ribani* D, M. Muñoz ${ }^{\dagger}$, E. Alves ${ }^{\dagger}$, J. P. Araujo , R. Bozzi ${ }^{\S}$, R. Charneca \\ F. Di Palma**, G. Etherington**, A. I. Fernandez ${ }^{\dagger}$, F. García ${ }^{\dagger}$, J. García-Casco ${ }^{\dagger}$, D. Karolyi ${ }^{\dagger \dagger}$,

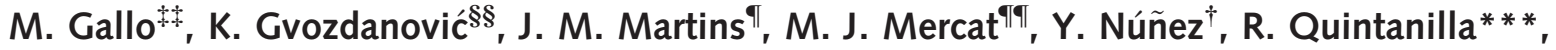

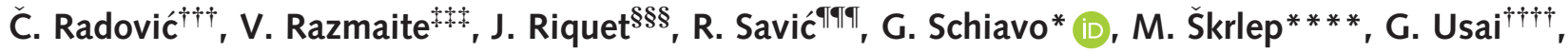 \\ V. J. Utzeri* (D, C. Zimmer ${ }^{*+4}$, C. Ovilo ${ }^{\dagger}$ (D) and L. Fontanesi* (D)
}

*Division of Animal Sciences, Department of Agricultural and Food Sciences, University of Bologna, Viale Fanin 46, Bologna 40127, Italy. 'Departamento Mejora Genética Animal, INIA, Crta. de la Coruña, km. 7,5, Madrid 28040, Spain. "Centro de Investigação de Montanha, Instituto Politécnico de Viana do Castelo, Escola Superior Agrária, Refóios do Lima, Ponte de Lima 4990-706, Portugal. ${ }^{\circledR}$ DAGRI - Animal Science Section, Università di Firenze, Via delle Cascine 5, Firenze 50144, Italy. "MED - Mediterranean Institute for Agriculture, Environment and Development, Universidade de Évora, Pólo da Mitra, Apartado 94, Évora 7006-554, Portugal. * *Earlham Institute, Norwich Research Park, Colney Lane, Norwich NR47UZ, UK. ${ }^{\dagger}$ Department of Animal Science, Faculty of Agriculture, University of Zagreb, Svetošimunska c. 25, Zagreb 10000, Croatia. Associazione Nazionale Allevatori Suini, Via Nizza 53, Roma 00198, Italy. ${ }^{\S}$ Faculty of Agrobiotechnical Sciences Osijek, University of Osijek, Vladimira Preloga 1, Osijek 31000, Croatia. "TIIFIP Institut Du Porc, La Motte au Vicomte, BP 35104 , Le Rheu Cedex 35651, France. ***Programa de Genética y Mejora Animal, IRTA, Torre Marimon, Caldes de Montbui, Barcelona 08140, Spain. ${ }^{\dagger \dagger}$ Department of Pig Breeding and Genetics, Institute for Animal Husbandry, Belgrade-Zemun 11080, Serbia. ${ }^{*}$ Animal Science Institute, Lithuanian University of Health Sciences, R. Žebenkos 12, Baisogala 82317, Lithuania. ${ }^{\$ \S}$ GenPhySE, INRA, Université de Toulouse, Chemin de Borde-Rouge 24, Auzeville Tolosane, Castanet Tolosan 31326, France. "9ף Faculty of Agriculture, University of Belgrade, Nemanjina 6, Belgrade-Zemun 11080, Serbia. ${ }^{* * *}$ Kmetijski Inštitut Slovenije, Hacquetova 17, Ljubljana SI-1000, Slovenia. ${ }^{\dagger \dagger}$ AGRIS SARDEGNA, Loc. Bonassai, Sassari 07100, Italy. ${ }^{\star \star *}$ Bäuerliche Erzeugergemeinschaft Schwäbisch Hall, Haller Str. 20, Wolpertshausen 74549, Germany.

Summary

In this study, we identified copy number variants (CNVs) in 19 European autochthonous pig breeds and in two commercial breeds (Italian Large White and Italian Duroc) that represent important genetic resources for this species. The genome of 725 pigs was sequenced using a breed-specific DNA pooling approach (30-35 animals per pool) obtaining an average depth per pool of $42 \times$. This approach maximised CNV discovery as well as the related copy number states characterising, on average, the analysed breeds. By mining more than 17.5 billion reads, we identified a total of $9592 \mathrm{CNVs}(\sim 683 \mathrm{CNVs}$ per breed) and 3710 CNV regions (CNVRs; $1.15 \%$ of the reference pig genome), with an average of 77 CNVRs per breed that were considered as private. A few CNVRs were analysed in more detail, together with other information derived from sequencing data. For example, the CNVR encompassing the KIT gene was associated with coat colour phenotypes in the analysed breeds, confirming the role of the multiple copies in determining breed-specific coat colours. The CNVR covering the MSRB3 gene was associated with ear size in most breeds. The CNVRs affecting the ELOVL6 and ZNF622 genes were private features observed in the Lithuanian Indigenous Wattle and in the Turopolje pig breeds respectively. Overall, the genome variability unravelled here can explain part of the genetic diversity among breeds and might contribute to explain their origin, history and adaptation to a variety of production systems.

Keywords copy number variant, ELOVL6, genetic resource, KIT, MSRB3, next-generation sequencing, Sus scrofa, ZNF622

Address for correspondence

L. Fontanesi, Division of Animal Sciences, Department of Agricultural

and Food Sciences, University of Bologna, Viale Fanin 46, 40127

Bologna, Italy.

E-mail: luca.fontanesi@unibo.it

Accepted for publication 30 April 2020 


\section{Introduction}

Livestock genomes have been shaped by natural and artificial selection, leading to the accumulation of a broad range of phenotypic and genetic variability that has largely contributed to the differentiation of populations into modern breeds. As a result, livestock populations and breeds represent a reservoir of genetic diversity, harbouring genetic variants that span from SNPs to more complex structural variants, some of which have small to large phenotypic effects on a variety of exterior and economically relevant traits (Andersen et al. 2011). Copy number variants (CNVs) are a type of structural variant in the form of large DNA segments, usually more than $1 \mathrm{~kb}$ in length, which are present in a variable copy number within a species as compared with its reference genome (Feuk et al. 2006).

Copy number variants represent an important source of genetic variability, by influencing phenotypes through a variety of molecular mechanisms such as gene dosage effect, disruption or alteration of coding and regulatory regions among several other modifications (Redon et al. 2006, Zhang et al. 2009; Bickhart \& Liu 2014). Detection of CNVs is technically challenging when applied on genomewide scale and various technologies have been applied to this aim. Among them, the most commonly used are array comparative genome hybridisation, high-density SNP chip and high-throughput sequencing (HTS) platforms (Winchester et al. 2009; Alkan et al. 2011; Pirooznia et al. 2015; Pollard et al. 2018). However, owing to the decreased cost of HTS analyses and the advantage that this approach has for obtaining more precise information on CNVs, wholegenome resequencing is becoming a standard approach to discover and characterise CNVs in complex genomes.

Genetic diversity described by $\mathrm{CNV}$ and $\mathrm{CNV}$ regions (CNVRs; i.e. CNVs present in different individuals in the same or overlapping genome regions) has been extensively studied in livestock, including, for example, cattle (Fadista et al. 2010; Bickhart et al. 2012), sheep (Fontanesi et al. 2011; Yang et al. 2018), goats (Fontanesi et al. 2010b; Liu et al. 2019), rabbits (Fontanesi et al. 2012) and chickens (Yi et al. 2014), among other species. Several studies investigating CNVs and CNVRs have also been reported in pigs, including also an interspecies survey within the genus Sus (Paudel et al. 2015). Studies have been focused on the main commercial European breeds (i.e. Duroc, Landrace, Large White, Hampshire, Yorkshire, Piétrain; e.g. Fadista et al. 2008; Chen et al. 2012; Li et al. 2012; Fowler et al. 2013; Wang et al. 2014, 2015a, 2015b, 2019a; Jiang et al. 2014; Revay et al. 2015; Wiedmann et al. 2015; Long et al. 2016; Revilla et al. 2017; Stafuzza et al. 2019) and Asian breeds (Meishan, Erhualian; Wang et al. 2012, 2014, 2015b, 2015c; Chen et al. 2012; Li et al. 2012; Jiang et al. 2014). Other studies have screened commercial pig populations in an attempt to capture some of the missing heritability (expected to be explained by CNVs) in economically important traits, including number of piglets born alive
(Stafuzza et al. 2019), fertility (Revay et al. 2015), meat quality traits (Wang et al. 2015c), fatty acid composition and growth traits (Revilla et al. 2017) and fat deposition (Fowler et al. 2013; Schiavo et al. 2014), among other traits.

Although the modern pig industry relies on a few commercial pig breeds, autochthonous pig populations subsist in many different regions, mainly associated with local and traditional niche markets (ॅ̌andek-Potokar \& Nieto Liñan 2019). These breeds represent genetic resources adapted to local agro-climatic and environmental conditions. To date, the genome architecture of CNVs has been studied mainly in Asian autochthonous populations/ breeds (Li et al. 2012; Wang et al. 2014, 2015b, 2019b; Jiang et al. 2014; Dong et al. 2015; Xie et al. 2016). European autochthonous pig breeds have been mainly investigated by exploring their genetic variability using SNP data (e.g. Ovilo et al. 2002; Tomás et al. 2011; Wilkinson et al. 2013; Silió et al. 2016; Yang et al. 2017; Muñoz et al. 2018a, 2018b; Muñoz et al. 2019; Ribani et al. 2019; Schiavo et al. 2018, 2019, 2020a, 2020b). A few studies, using SNP arrays, have analysed CNVs in European autochthonous pig breeds (e.g. Iberian, Swallow-Bellied Mangalitsa; Ramayo-Caldas et al. 2010; Fernández et al. 2014; Molnár et al. 2014).

Results of CNV studies in pigs show a limited degree of agreement in terms of CNVR number and size ranges. Even if some of these discrepancies may be attributed to breedspecific genome features, the remainder may derive from the different technologies and algorithms used to unravel CNVs, mainly array comparative genome hybridisation and SNP arrays. Few other studies have analysed CNVs and CNVRs in the pig genome using HTS platforms (e.g. Rubin et al. 2012; Jiang et al. 2014; Paudel et al. 2015; Wang et al. 2015a, 2019b; Keel et al. 2019; Long et al. 2016; Revilla et al. 2017).

In this study, we provide a detailed survey of CNVs and CNVRs in the pig genome by whole-genome resequencing of DNA pools constituted from 21 European pig breeds: 19 autochthonous breeds belonging to nine different countries and two Italian commercial breeds. These breeds, some of them untapped, stem from different production systems and breeding programmes in Europe. Therefore, dissection of their genome architecture at the level of CNVs could provide new insights into their histories, origin, potential selection signatures and adaptation to different local agro-climatic and environmental conditions.

\section{Materials and methods}

\section{Animals}

Blood samples were collected from 30 or 35 animals from each of the 21 pig breeds included in the study, distributed across nine European countries (from west to east and then north; Fig. 1): Portugal (Alentejana and Bísara), Spain 


\section{Autochthonous pig breeds}

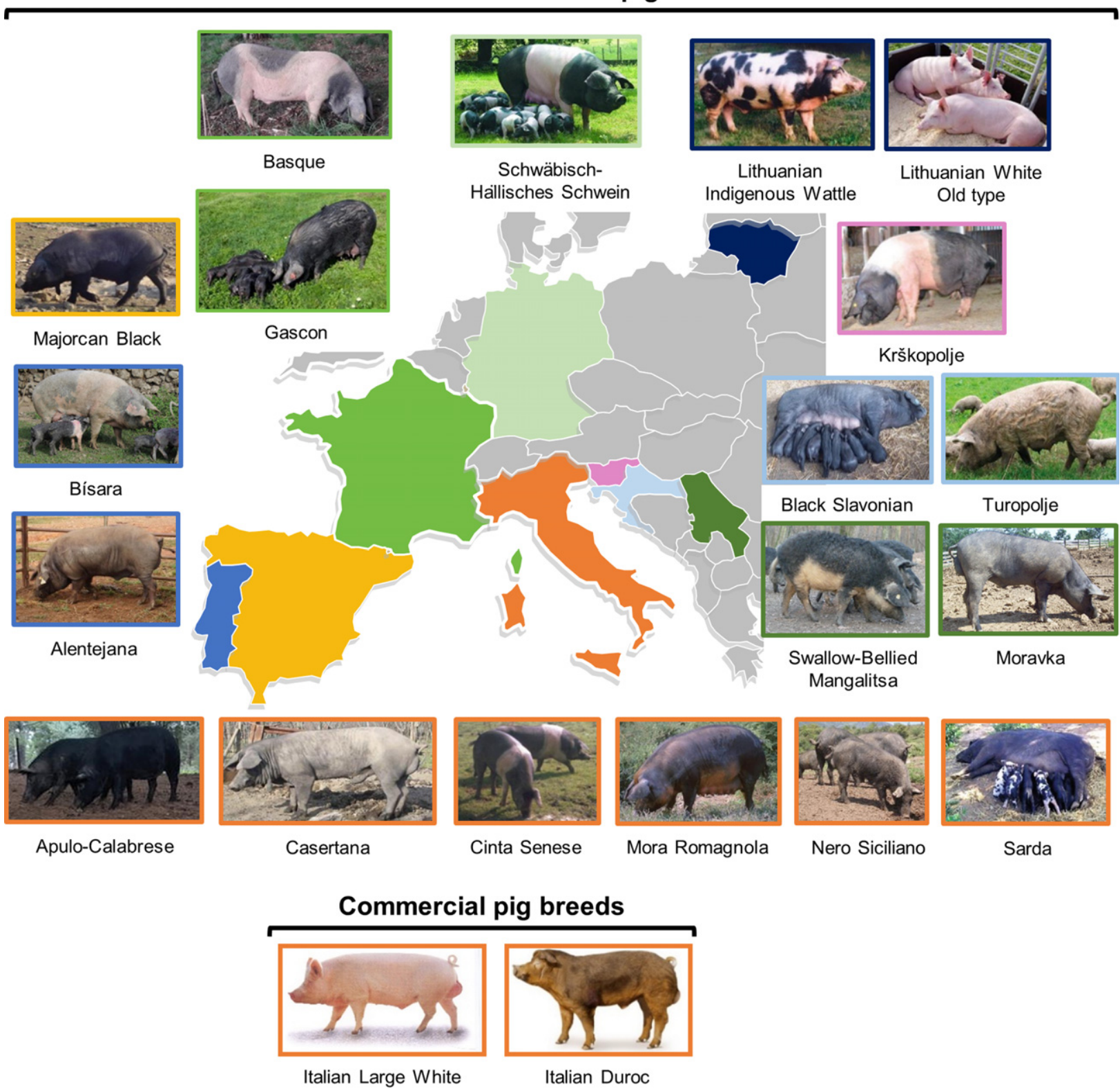

Figure 1 Phenotypes and geographical origin of the 21 analysed pig breeds.

(Majorcan Black), France (Basque and Gascon), Italy (autochthonous - Apulo-Calabrese, Casertana, Cinta Senese, Mora Romagnola, Nero Siciliano and Sarda; and commercial breeds - Italian Large White and Italian Duroc), Slovenia (Krškopolje Pig, hereafter indicated as Krškopolje), Croatia (Black Slavonian and Turopolje), Serbia (Moravka and Swallow-Bellied Mangalitsa), Germany (SchwäbischHällisches Schwein) and Lithuania (Lithuanian Indigenous Wattle and Lithuanian White Old Type). Selection of individuals for sampling was performed by avoiding highly related animals (no full or half-sibs), balancing between sexes, and prioritising adult individuals or at least animals with adult morphology. All animals were registered to their respective Herd Books and presented standard breed characteristics. Details of the analysed animals and investigated breeds, including geographical distribution and phenotypic description, are reported in Table S1.

\section{DNA samples and sequencing}

Genomic DNA was extracted from 8-15 ml of peripheral blood for each pig, collected in Vacutainer tubes containing $10 \% \quad 0.5 \mathrm{~m}$ EDTA (ethylenediaminetetraacetic acid, disodium dihydrate salt) at $\mathrm{pH}$ 8.0. The extraction was performed using either a standardised phenol-chloroform (Sambrook et al. 1989) or the NucleoSpin ${ }^{\circledR}$ Tissue 
commercial kit (Macherey-Nagel, Düren, Germany). A total of 21 DNA pools were constructed, including in each pool 30 or 35 individual DNA samples pooled at equimolar concentrations (Table S2).

A sequencing library was generated for each DNA pool using the Truseq ${ }^{\circledR}$ Nano DNA HT sample preparation kit (Illumina, CA, USA), following the manufacturer's recommendations. Briefly, DNA was randomly sheared to obtain $350 \mathrm{bp}$ fragments which were end polished, A-tailed, and ligated with the full-length adapter for Illumina sequencing with further PCR amplification. PCR products were purified (AMPure XP system) and libraries were analysed for size distribution using an Agilent 2100 Bioanalyser and quantified using real-time PCR. The qualified libraries were then fed into an Illumina Hi-Seq sequencer for paired-end sequencing, obtaining $150 \mathrm{bp}$ length reads.

\section{Quality controls and sequence alignment}

Obtained reads underwent several cleaning and filtering steps including removal of (i) adapters, (ii) reads containing more than $10 \%$ unknown bases $(N)$ and (iii) reads containing low-quality bases $(Q \leq 5)$ over $50 \%$ of the total sequenced bases. FASTQ files were subsequently inspected using FASTQC version 0.11.7 (https://www.bioinformatic s.babraham.ac.uk/projects/fastqc/), which highlighted high-quality reads.

Reads were mapped on the latest version of the Sus scrofa reference genome (Sscrofa11.1) with BWA tool 0.7.17 (Li \& Durbin, 2009; function, MEM) and the parameters for paired-end data. PICARD version 2.1.1 (https://broadinstitute. github.io/picard/) was used to remove duplicate reads. Whole-genome sequencing data statistics are reported in Table S2.

\section{Detection of CNVs and CNVRs from sequencing data}

The CN.mops version 1.32 tool (Klambauer et al. 2012) was used to identify autosomal CNVs. CN.MOPs was run with default parameters except for the window size, which was lowered to $750 \mathrm{bp}$. As three consecutive genome windows positive for copy number are required by CN.MOPs to assert the presence of a $\mathrm{CNV}$, the minimum size of a detected $\mathrm{CNV}$ was $2250 \mathrm{bp}$. The $750 \mathrm{bp}$ window size allowed us to detect short CNVs (CNV $\geq 3 \mathrm{kbp}$ with default parameters) with a length fitting the definition of $\mathrm{CNV}$ (usually more than $1 \mathrm{kbp}$ ). Smaller window sizes were tested resulting in longer computational times without any specific indication of their reliability. CNVs identified in the different breeds were merged into CNVRs with BEDTOOLS version 2.17.0 (Quinlan \& Hall 2010; function, merge) whenever overlapping genome windows, constituting the different CNVs, were encountered.

Copy number variant regions were then compared with previous studies. The comparison was carried out by remapping CNVRs on SSCROFA11.1 using the NCBI genome remapping tool (https://www.ncbi.nlm.nih.gov/genome/ tools/remap), looking for CNVRs sharing at least one nucleotide, as proposed by Keel et al. (2019).

\section{Cluster analysis of breeds based on CNVRs}

Pig breeds were clustered based on the read count ratio of each genome window covered by a CNVR. This ratio was defined as $\mathrm{RC} / \mathrm{RC}_{\mathrm{g}}$, where $\mathrm{RC}$ and $\mathrm{RC}_{\mathrm{g}}$ indicate the exact number and the average number of reads in a genome window for a specific pig breed, respectively. Hierarchical clustering was computed in $\mathrm{R}$ version 3.6 ( $\mathrm{R}$ Core Team 2018; function: hclust) using the Ward.D2 distance (we excluded genome windows presenting a ratio $\geq 50$ in at least one pig breed).

\section{Genomic analysis of repeated elements in CNVs/CNVRs and flanking regions}

The GFF file reporting the location of repeated elements interspersed in the $S$. scrofa genome was downloaded from the UCSC Genome Browser (https://genome.ucsc.edu/). For CNVs/ CNVRs and the related $1 \mathrm{~kb}$ flanking regions, we counted the number of bases overlapping each repeated element (BEDTOOLS; function: intersect), assessing their enrichment via Fisher's exact test as implemented in PYTHON 2.6 (Scipy library; function: stats.fisher_exact; alternative hypothesis: greater). We considered statistically enriched classes of repeated elements presenting a $P<0.05$, Bonferroni corrected.

\section{Annotation of CNVRs}

Annotated genes overlapping the identified CNVRs were retrieved from the Sscrofa11.1 NCBI GFF file using BEDTOOLS (function: intersect). Functional analysis was carried out with PANTHER (Mi et al. 2019) via Fisher's exact test. Analyses were run over a subset of the GO - Biological Process resource (PANTHER GO-SLIM version 14.1; release 2019-03-12; no. $=2004$ biological processes) and the REACTOME database (REACTOME version 65; release 2019-0312 ; no. $=1569$ pathways). We made use of pig-specific gene annotations. We considered statistically enriched terms presenting a $P<0.05$, False Discovery Rate (FDR) corrected.

The presence of QTL in CNVRs was evaluated and tested via Fisher's exact test. QTL were downloaded from the Pig Quantitative Trait Locus Database (release 39; Hu et al. 2019) and checked. Distribution of QTL size pointed out a fraction of long QTL ( $>2 \mathrm{Mbp}$ ) probably owing to a lack of resolution derived by the information retrieved from several QTL studies. These QTL were discarded. We noted that, for a given QTL class (i.e. trait), several DNA markers, defining the QTL in different breeds, were close to each other. Thus, QTL that were less than $500 \mathrm{kbp}$ distance were merged with BEDTOоLs (function: merge) to obtain QTL regions. The final dataset presented a total of 295 traits and 1978 QTL regions. For each trait, the fraction of CNVR nucleotides 
overlapping QTL was retrieved with BEDTOoLs (function: intersect). Fisher's exact test was run in PYTHON, retrieving statistically enriched traits presenting a $P<0.05$, Bonferroni corrected.

\section{Results}

Sequenced reads and genome-wide identification of CNVs

About 17.5 billion reads were produced from the sequencing of the 21 pig DNA pools. On average, each DNA pool presented about 417.7 million of mapped reads spanning $98.5 \%$ of the $S$. scrofa reference genome, with an average read depth of about $42 \times$. Summary statistics of sequencing data are reported in Table S2.

Using CN.MOPs we identified a total of 9592 CNVs (14 344 events) across the 21 analysed breeds. On average, each pig breed had 683 CNVs (median, 601; minimum, 209, Sarda; maximum, 1440 Turopolje) covering $0.18 \%(\mathrm{SD}=0.09 \%)$ of the reference genome, with the smallest fraction in Sarda $(0.04 \%)$ and the largest coverage in Turopolje $(0.40 \%)$, reflecting the lowest and highest number of $\mathrm{CNVs}$ respectively (Table 1). For each pig breed, CNVs were divided into losses (copy number $<2$, as inferred by cN.MOPS) and gains (copy number $>2$, as inferred by CN.MOPs) that represented the most frequent copy number $(\mathrm{CN})$ state characterising the animals analysed in the pools. On the whole, we identified a total of 3492 losses, 5012 gains and 638 showing a mix of $\mathrm{CN}$ loss and gain. The losses/gains ratio was around 0.79. Stratified by chromosome, this value ranged from 0.57 to 1.02 , for SSC12 and SSC1 respectively (Table S3). Considering the CNVs detected in each breed, the number of losses and gains strongly correlated $(r=0.93)$. CNV length ranged from 2250 to $560250 \mathrm{bp}$. The longest CNV (560 $250 \mathrm{Mbp}$ ) was detected on SSC8 in the Italian Large White and Lithuanian White Old Type pig breeds (Table 1). The number of CNVs and the chromosome length had a medium to high Pearson's correlation coefficient $(r=0.69 ; P<0.05)$.

\section{Identification of CNVRs}

Copy number variants were merged across breeds resulting in a total of 3710 CNVRs (Table S4). The distribution of CNVRs along each chromosome is presented in Fig. 2. SSC1, SSC2 and SSC3 had the largest number of detected CNVRs ( $n=359,361$ and 307 respectively; Table 2). The

Table 1 Summary of copy number variants (CNVs) of the 21 analysed pig breeds. Data are stratified by breed

\begin{tabular}{|c|c|c|c|c|c|c|c|c|}
\hline Breed & Short name & $\mathrm{CNV}^{1}$ & $\mathrm{CNL}^{2}$ & $\mathrm{CNG}^{3}$ & Length $_{\text {Min }}{ }^{4}$ & Length $_{\operatorname{Max}}{ }^{5}$ & Length $_{\text {Median }}{ }^{6}$ & Percentage length in $\mathrm{CNV}^{7}$ \\
\hline \multicolumn{9}{|l|}{ Autochthonous } \\
\hline Alentejana & $\mathrm{AL}$ & 601 & 345 & 256 & 2250 & 69750 & 3000 & 0.17 \\
\hline Apulo-Calabrese & $A C$ & 676 & 313 & 363 & 2250 & 142500 & 3000 & 0.18 \\
\hline Basque & BA & 1122 & 626 & 496 & 2250 & 99750 & 3750 & 0.29 \\
\hline Bísara & $\mathrm{Bl}$ & 437 & 162 & 275 & 2250 & 63000 & 3000 & 0.11 \\
\hline Black Slavonian & BS & 504 & 225 & 279 & 2250 & 142500 & 3000 & 0.13 \\
\hline Casertana & $C A$ & 596 & 272 & 324 & 2250 & 113250 & 3000 & 0.16 \\
\hline Cinta Senese & CS & 662 & 352 & 310 & 2250 & 89250 & 3750 & 0.19 \\
\hline Gascon & GA & 781 & 379 & 402 & 2250 & 126000 & 3000 & 0.20 \\
\hline Krškopolje & $\mathrm{KR}$ & 510 & 152 & 358 & 2250 & 101250 & 3000 & 0.13 \\
\hline Lithuanian Indigenous Wattle & LIW & 710 & 295 & 415 & 2250 & 90750 & 3750 & 0.19 \\
\hline Lithuanian White Old Type & LWOT & 711 & 308 & 403 & 2250 & 560250 & 3750 & 0.21 \\
\hline Majorcan Black & $\mathrm{MB}$ & 546 & 328 & 218 & 2250 & 101250 & 3750 & 0.15 \\
\hline Mora Romagnola & MR & 1255 & 647 & 608 & 2250 & 137250 & 3000 & 0.34 \\
\hline Moravka & MO & 391 & 159 & 232 & 2250 & 100500 & 3000 & 0.10 \\
\hline Nero Siciliano & NS & 298 & 149 & 149 & 2250 & 42750 & 3000 & 0.07 \\
\hline Sarda & SA & 209 & 72 & 137 & 2250 & 38250 & 3000 & 0.04 \\
\hline Schwäbisch-Hällisches Schwein & SHS & 576 & 277 & 299 & 2250 & 147000 & 3000 & 0.15 \\
\hline Swallow-Bellied Mangalitsa & SBMA & 757 & 433 & 324 & 2250 & 121500 & 3000 & 0.22 \\
\hline Turopolje & TU & 1440 & 845 & 595 & 2250 & 99750 & 3750 & 0.40 \\
\hline \multicolumn{9}{|l|}{ Commercial } \\
\hline Italian Duroc & IDU & 1111 & 249 & 862 & 2250 & 116250 & 3000 & 0.28 \\
\hline Italian Large White & ILW & 451 & 148 & 303 & 2250 & 560250 & 3000 & 0.14 \\
\hline
\end{tabular}

${ }^{1}$ Total number of copy number variants.

${ }^{2}$ Total number of copy number losses.

${ }^{3}$ Total number of copy number gains.

${ }^{4}$ Minimum length (bp) of CNVs.

${ }^{5}$ Maximum length (bp) of CNVs.

${ }^{6}$ Median length (bp) of CNVs.

${ }^{7}$ Percentage of the Sus scrofa genome occupied by CNVs. 


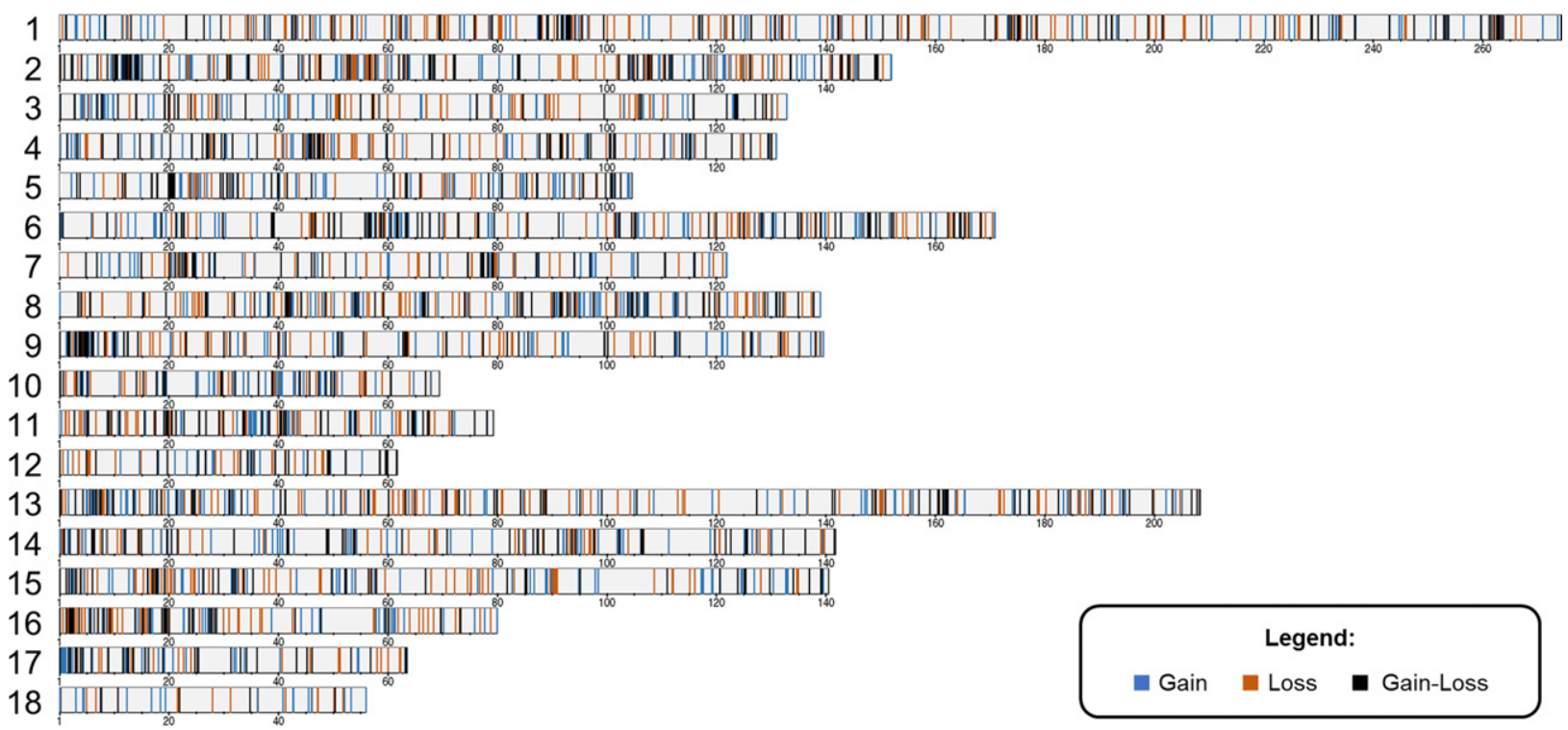

Figure 2 Distribution of copy number variant regions (CNVRs) along each autosomal chromosome.

Table 2 Summary of CNV regions (CNVRs) of the 21 analysed pig breeds stratified by chromosome

\begin{tabular}{|c|c|c|c|c|c|}
\hline Chromosome & $\mathrm{CNVR}^{1}$ & Length $_{\operatorname{Min}}{ }^{2}$ & Length $_{\operatorname{Max}}{ }^{3}$ & Length $_{\text {Median }}{ }^{4}$ & Percentage length in $\mathrm{CNVR}^{5}$ \\
\hline SSC1 & 359 & 2250 & 137250 & 3760 & 0.88 \\
\hline SSC2 & 361 & 2250 & 43500 & 3760 & 1.54 \\
\hline SSC3 & 162 & 2250 & 147750 & 3010 & 0.82 \\
\hline SSC4 & 227 & 2250 & 81000 & 3760 & 0.99 \\
\hline SSC5 & 215 & 2250 & 46500 & 3760 & 1.45 \\
\hline SSC6 & 302 & 2250 & 120750 & 3760 & 1.07 \\
\hline SSC7 & 167 & 2250 & 96750 & 3760 & 1.16 \\
\hline SSC8 & 244 & 2250 & 560250 & 3760 & 1.37 \\
\hline SSC9 & 259 & 2250 & 159000 & 3760 & 1.86 \\
\hline SSC10 & 114 & 2250 & 85500 & 3010 & 0.96 \\
\hline SSC11 & 159 & 2250 & 153750 & 3760 & 1.54 \\
\hline SSC12 & 110 & 2250 & 108000 & 3385 & 1.33 \\
\hline SSC13 & 307 & 2250 & 91500 & 3760 & 1.05 \\
\hline SSC14 & 212 & 2250 & 195750 & 3760 & 1.34 \\
\hline SSC15 & 196 & 2250 & 63000 & 3760 & 0.86 \\
\hline SSC16 & 138 & 2250 & 41250 & 3010 & 0.88 \\
\hline SSC17 & 132 & 2250 & 80250 & 3010 & 1.27 \\
\hline SSC18 & 46 & 2250 & 16500 & 3010 & 0.35 \\
\hline
\end{tabular}

${ }^{1}$ Total number of copy number variant regions.

${ }^{2}$ Minimum length (bp) of CNVs.

${ }^{3}$ Maximum length (bp) of CNVs.

${ }^{4}$ Median length (bp) of CNVs.

${ }^{5}$ Percentage of the chromosome occupied by CNVRs.

number of CNVRs and the chromosome length were highly correlated $(r=0.87 ; P<0.05)$. Positive correlation $(r=0.92, P<0.05)$ was also observed between the number of CNVRs and their total length. On average, each pig breed had 586 CNVRs (minimum: 180 in Sarda; maximum: 1257 in Turopolje; Table S5). Among the 3710 CNVRs, 1615 (43.5\%) were breed-specific (and indicated as private CNVRs; Table S5). The size of CNVRs ranged from 2250 to $560250 \mathrm{bp}$ (the same as CNVs), with an average length of $7038 \mathrm{bp}$ and a median value of $3750 \mathrm{bp}$ (Table 2). Distribution of CNVR size showed a decrease in CNVR counts while increasing their size. CNVRs occupied a total of $26.1 \mathrm{Mbp}$, equal to $1.15 \%$ of the SSCROFA11.1 reference genome. Among the CNVRs, based on the $\mathrm{CN}$ state (i.e. the number of copies; $\mathrm{CN}$ state) provided by CN.MOPS, 1305 (35.2\%) had only CN gains (duplication), 
1323 (35.6\%) had only CN losses (deletion) and 1082 (29.2\%) showed a mix of $\mathrm{CN}$ losses and gains from different pig breeds.

The 3710 detected CNVRs encompassed a total of 34821 genome windows. After filtering, the read count ratio of each genome window was used to cluster pig breeds (Fig. 3), which grouped breeds in agreement woth their main specific phenotypes or their geographic origin. The first group encompassed breeds that have a coat colour with white background or white patterns (Lithuanian Indigenous Wattle, Italian Large White, Krškopolje, Bísara and Lithuanian White Old Type). This may be due to the strong signals of genome windows encompassing the KIT gene that accounts for approximately $15 \%$ of the total positive windows for CNVs. The two reddish-brown-coloured breeds (Mora Romagnola and Italian Duroc) were on the same branch. Three autochthonous Italian breeds (Casertana, Nero Siciliano and Sarda) constituted a cluster whereas one Portuguese and one Spanish breed (Alentejana and Majorcan Black respectively) constituted another cluster. The Turopolje pig breed was the only one that clustered apart from all other breeds.

\section{Repeated elements within and flanking CNVs and CNVRs}

Highly repetitive sequences were investigated for their cooccurrence with CNVs and CNVRs (Table S6). The following classes of repeated elements were statistically over-represented within CNVs: LINEs, LTRs, satellites, rolling-circle (RC/Helitron) and pseudogenes (tRNAs, snRNAs, srpRNAs and rRNAs). Additionally, CNV flanking regions (1 kbp per side) were enriched for the following classes: SINEs, simple repeat and low complexity. CNVRs differed in the absence of RC elements and the absence of SINEs and srpRNAs in the 1

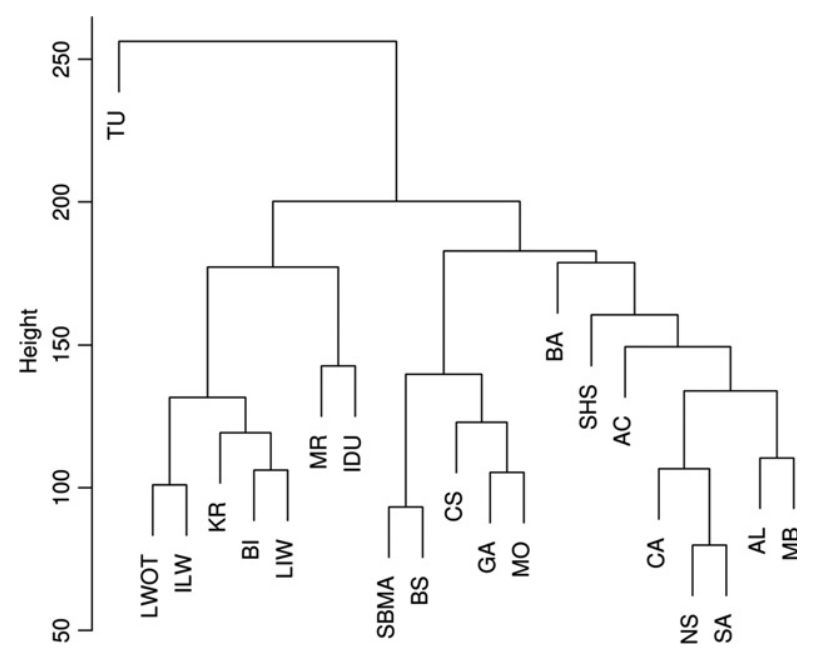

Figure 3 Dendrogram representing the hierarchical clustering of the copy number state. Acronyms of the breed name are explained in Table 1 kbp flanking regions. However, SINEs were over-represented when the flanking region size was extended to $10 \mathrm{kbp}$.

\section{QTL in CNVRs}

A total of 1978 QTL regions, associated with 554 phenotypic traits, were retrieved from the pig QTL database. CNVRs overlapped a total of 336 QTL regions representing 295 phenotypic traits. Enrichment analysis identified 126 traits $(\sim 43 \%)$ that were significantly over-represented $(P<0.05$, Bonferroni corrected). These traits spanned various classes, including meat quality, body shape and conformation, reproduction, disease susceptibility, haematological and metabolism-related traits (Table S7).

\section{Functional annotation of CNVRs and detailed analysis of} selected genes

A total of 1571 genes overlapped the identified CNVRs, including 1296 protein-coding genes, 261 lncRNAs, three miRNAs and 11 tRNAs. The number of overlapped genes correlated with the number of CNVRs $(r=0.99)$. A total of 993 protein-coding genes were annotated by PANTHER and used for functional enrichment over the GO-slim Biological process resource. A total of 17 terms were over-represented (Table S8), encompassing various biological processes such as sensory perception, nervous system process, fatty acid metabolic process, gene expression and biological adhesion. Over the REACTOME database, PANTHER over-represented the olfactory signalling pathway and the related mechanism of transduction mediated by $\mathrm{G}$ protein-coupled receptors (Table S8). Analysis of genes located in private CNVRs did not identify any over-represented process/pathway.

The v-kit Hardy-Zuckerman 4 feline sarcoma viral oncogene homolog (KIT) and the methionine sulfoxide reductase $B 3$ (MSRB3) genes are two important genes presenting variable copies among breeds. CNVs affecting the KIT gene are responsible for different coat colour phenotypes (Johansson et al. 1996; Marklund et al. 1998; Johansson et al. 2005; Rubin et al. 2012), whereas variable copies of the MSRB3 have been associated with ear size in pigs (Chen et al. 2018).

Detailed analysis of the KIT gene indicated the presence of the four duplicated regions (DUP1-4; Fig. 4a) previously described by Rubin et al. (2012). Structural variants as well as the presence of the splice mutation at the first base in intron 17 (g.41486012G $>$ A, rs345599765) are required for a solid white coat colour (Marklund et al. 1998). Using sequence data, we estimated the allele frequencies of this SNP (Fig. 4a; Table S9) to complement CNV results. Pools from coloured pigs did not show any CNVs and the splice mutation. White pigs (Italian Large White and Lithuanian White Old Type) had DUP1-4 and the splice mutation (allele A). However, allele frequencies were divergent (Table S9), suggesting a different structure of the CNV 

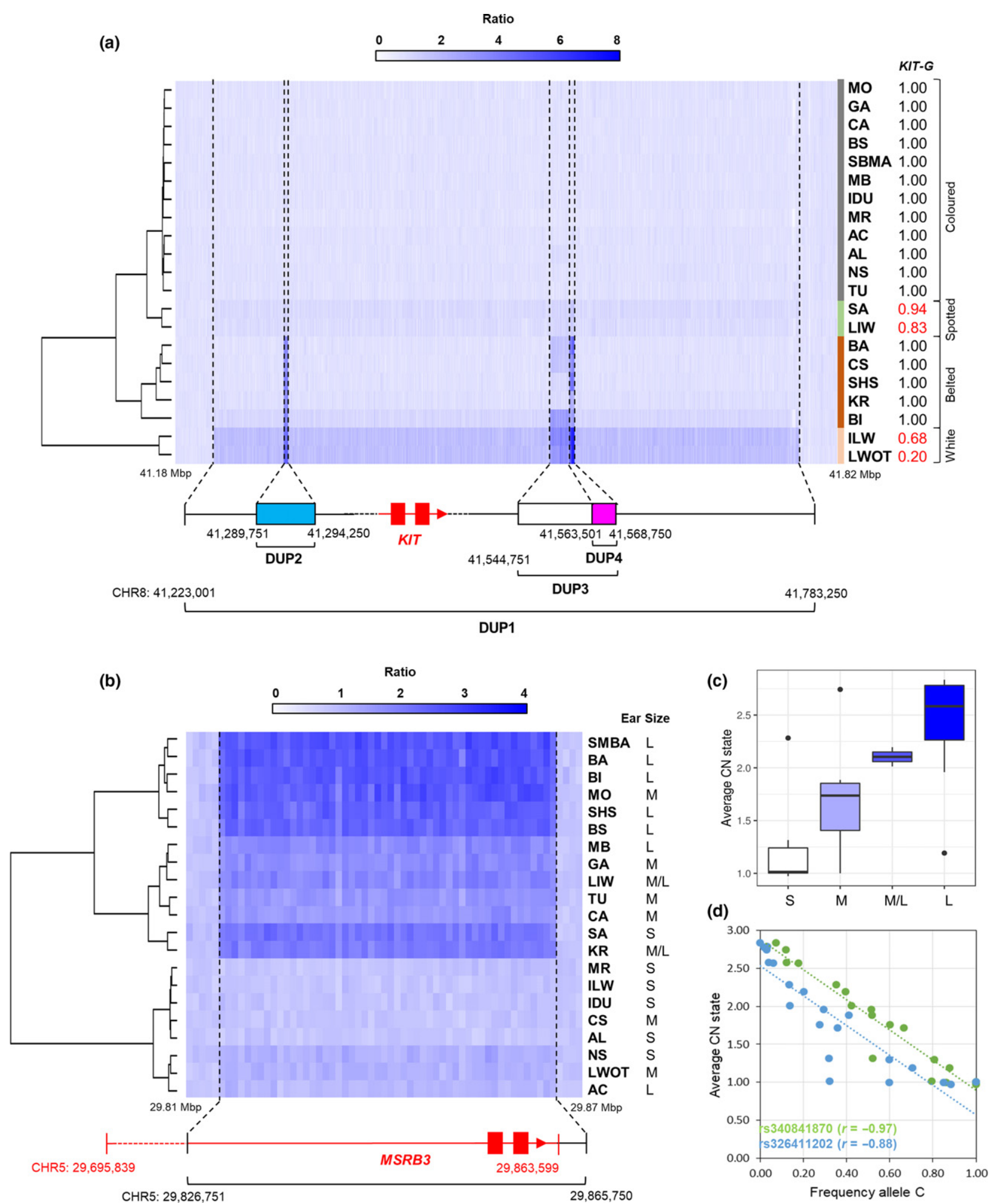

Figure 4 (a) Heatmap of the read count ratios over the KIT gene. Coat colour reported in the correspondence of the breeds indicates the main breed characteristics. SA (Sarda) has heterogeneous and not-fixed patterns. It was included among the spotted based on the frequency of this phenotype in the breed and according to the copy number (CN) state at this locus. Basque (BA) has spotted/belted heterogeneous patterns but was included among the belted breeds according to the CN state at this locus (see text and Table S1 for details). KIT-G, Frequency of the allele G of the SNP rs345599765 (splice mutation of the intron 17; Marklund et al. 1998). (b) Heatmap of the read count ratios over the MSRB3 gene. Ear size indicated in (b): L, large; $M$, medium; S, small (see text and Table S1 for details). The light-dark blue bar at the top of (a) and (b) indicates the CN ratio ( 1 = normal state without any gain or loss). For each breed, the read count ratio was computed in 750 bp consecutive genome windows. Acronyms of the breed name are explained in Table 1. (c) Average CN state of the MSRB3 gene in relation to ear size. (d) Relationship between the average CN state of the MSRB3 gene and the SNPs rs340841870 (green) and rs326411202 (blue). Pearson's correlation coefficient ( $r$ ) is reported. 
(different gene copies with the A or G nucleotides). The Sarda (not fixed for any coat colour and including many spotted animals) and Lithuanian Indigenous Wattle breeds presented DUP1, did not have DUP2-4 and had allele A (the only two other breeds having the splice mutation). Bísara, another spotted breed, had also DUP2-3. The piebald breed Basque and the belted breed Cinta Senese had DUP2-4, whereas the other two belted breeds (Krškopolje and Schwäbisch-Hällisches Schwein) had only DUP2 and DUP4.

The detailed analysis of the MSRB3 gene region revealed the presence of the $38.4 \mathrm{kbp}$ duplication (SSC5:2982698129865653; Fig. 4b) previously described by Chen et al. (2018). Copy number gains encompassing the MSRB3 exons 6 and 7 have been associated with large ear size in Chinese pig breeds and with half-floppy ears in Landrace pigs (Chen et al. 2018). Alentejana, Cinta Senese, Mora Romagnola, Italian Duroc and Italian Large White, which are breeds characterised by small/medium ear size, had a normal $\mathrm{CN}$ state (which means no gain of copies). The remaining pig breeds showed variable $\mathrm{CN}$, which seems to be correlated to ear size (Fig. 4c). Regression analysis between the average $\mathrm{CN}$ state and the ear size (coded as follows: small, 1; medium, 1.5; medium/large, 1.75; and large, 2) resulted in a positive association $(P=0.0001)$. However, other breeds characterised by small ears (i.e. Nero Siciliano and Sarda) had variable CNs. Variability in ear size was also analysed by estimating the allele frequency of two $\mathrm{SNP}$ in the $5^{\prime}$ flanking region (g.29695369C $>\mathrm{T}$; rs340841870) and in the $3^{\prime}$-untranslated region (g.29862412C>T; rs326411202) of the MSRB3 gene, that Zhang et al. (2015) reported to be associated with ear size. These SNP positions are not included in the CNVR of this gene. For each SNP, the regression analysis pointed out a significant association between allele frequencies and ear size $(P<0.0001)$. Additionally, allele frequencies of these two SNPs (Table S9) correlated with the average CN state (| $r \mid>0.8 ; P<0.0001$; Fig. 4d).

We further explored genomic regions harbouring private information on CNVRs. Among them, we identified two interesting examples. The first one, characterising Lithuanian Indigenous Wattle pigs, encompassed the intron 10 of the ELOVL fatty acid elongase 6 (ELOVL6) gene (Fig. 5a). Variants in this gene have been associated with fatty acid composition in pigs (Corominas et al. 2013). The second one, characterising Turopolje pigs, was the Zinc finger protein 622 (ZNF622) gene, a regulator of early embryonic development (Hasegawa et al. 2015). The CNV affecting this gene was quite complex. Copy number gains were in the correspondence of the exonic regions but also included the complete introns 1,2 and 5. Most of introns 3 and 4 were not affected by $\mathrm{CN}$ gains (only small and contiguous intronic segments to the exonic regions were included in the $\mathrm{CN}$ gains; Fig. 5b). The regions with $\mathrm{CN}$ gains were clearly evidenced in all breeds except Turopolje, which did not have any $\mathrm{CN}$ and, in part, Krškopolje and Italian Duroc, which had CNs higher than that of Turopolje but lower than those of all other breeds (Fig. 5b).

\section{Comparison with other studies}

The positions of CNVRs we detected were compared with the CNVRs reported by previous studies, which analysed different pig breeds and other species of the Sus genus using whole-genome sequencing. A total of five datasets, which investigated Asian pig breeds, commercial and European pig breeds, and five species of the genus Sus, were considered for this comparison (Table $\mathrm{S} 4$ ). The overlap ranged from about 10 to $25 \%$ (Table S10). Overall, a total of 595 CNVRs detected in our work (16\%) overlapped with CNVRs reported by the considered studies (Table S4).

\section{Discussion}

In this study, we carried out a genome-wide CNV/CNVR analysis in 19 European autochthonous and two Italian commercial pig breeds. Breeds were analysed using a wholegenome sequencing strategy from breed-specific DNA pools to maximise CNV discovery. CNVs were detected via CN.MOPS, a tool that implements a Bayesian approach that models depth of coverage across samples by decomposing its variability in part from $\mathrm{CNs}$ and the remaining part owing to noise, in order to reduce false discoveries (Klambauer et al. 2012). Other software based on different assumptions has been also developed and used for CNV detection from HTS datasets. However, there is no consensus in the literature on the strategy and methodology that might be applied for this purpose.

As our study was based on DNA pools from a large number of populations, we maximised the power of CN.MOPS in reducing the FDR, as this tool is specifically designed to deal with multiple samples.

Even if this design could not precisely define the exact number of copy gains or losses for all animals in the sequenced pools, the obtained results made it possible to capture within-breed averaged states. This was supported by the agreement among the different coat colour phenotypes and the expected $\mathrm{CN}$ states, correctly detected at the KIT locus, which indirectly confirmed and validated CNV calls from cN.MOPs. This approach demonstrated that CNVs detected using whole-genome sequencing can be useful to identify breed-specific features (including in this definition the most frequent breed features) and describe genetic diversity across pig breeds, complementing SNP-based studies.

We confirmed a high correspondence between CNV data detected from sequenced DNA pools and SNP information using Pearson's correlation calculated considering the fraction of the pig genome covered by CNVRs detected for each breed (Table 1) and SNP-based diversity measured on the same animals genotyped with the GeneSeek ${ }^{\circledR}$ GGP 
Bovo et al.

(a)

Ratio

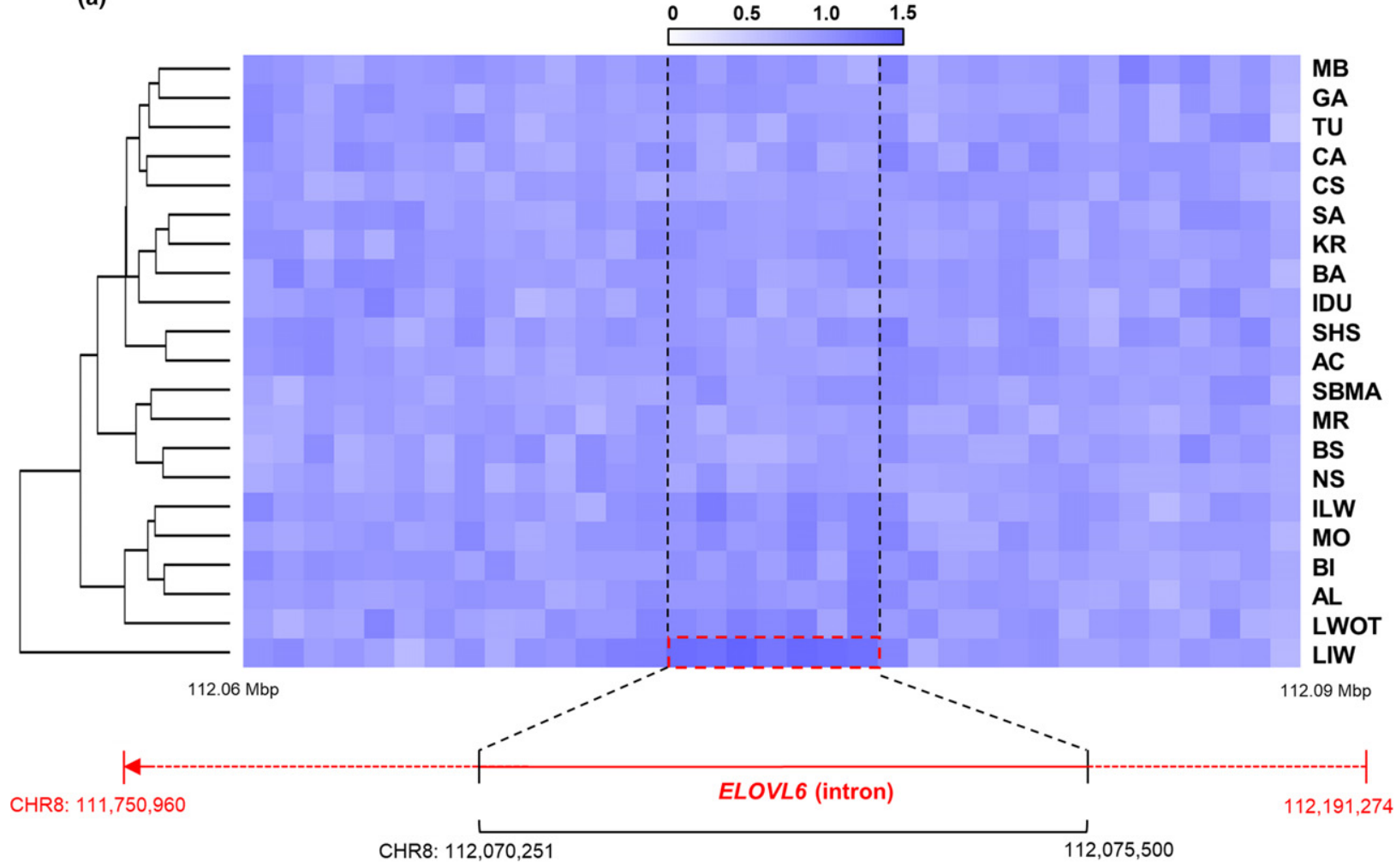

(b)

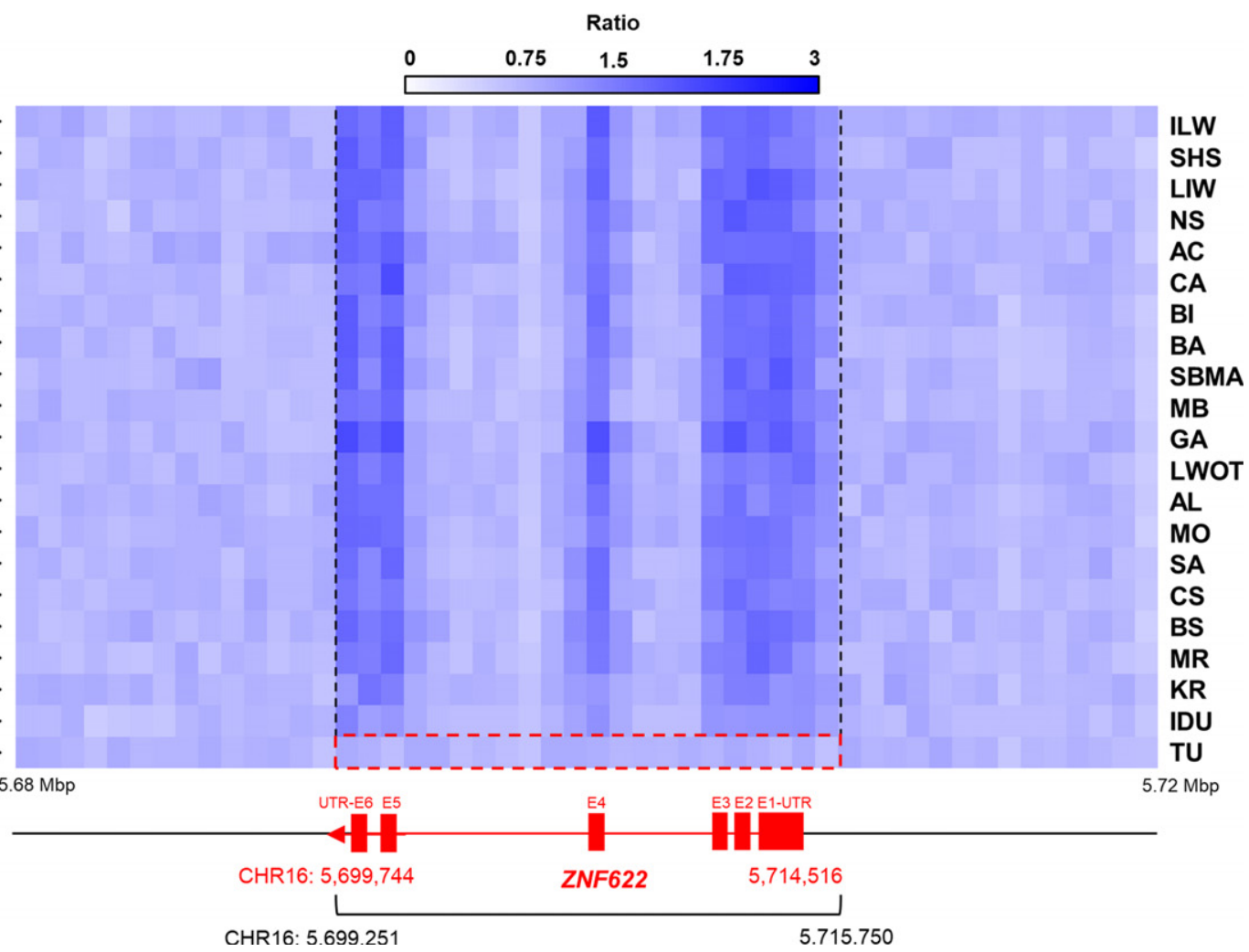

Figure 5 Heatmap of the read count ratios over the ELOVL6 (a) and ZNF622 (b) genes. Exons below the heatmap for the ZNF622 gene are numbered (E1-E6) according to the annotation in the SSCROFA11.1 genome version. UTRs are also reported. The light-dark blue bar at the top of (a) and (b) indicates the $\mathrm{CN}$ ratio ( 1 = normal state without any gain or loss). For each breed, the read count ratio was computed in 750 bp consecutive genome windows. Acronyms of the breed name are explained in Table 1. 
Porcine HD Genomic Profiler (Muñoz et al. 2019). Among these SNP averaged variability parameters, correlation with the above-mentioned CNVR parameter was highly negatively correlated with both the MAF $(r=-0.90)$ and expected heterozygosity $(r=-0.90)$, whereas highly positive correlated with the fixation index $\left(F_{\mathrm{ST}} ; r=0.96\right)$ values. These correlations mean that when within-breed variability was low, it increased the possibility of identifying losses/ gains at variable $\mathrm{CN}$ state and that the fraction of the genome covered by CNVRs detected in DNA pools is a good indicator of the diversity among breeds.

With few differences, these breeds were clustered resembling the relationships that we had already reported using array SNP datasets obtained from individually genotyped pigs and SNPs detected from whole-genome sequencing (Muñoz et al. 2018a, 2018b; Muñoz et al. 2019; Bovo et al. in preparation). Geographical and some major morphological features (i.e. coat colour) mainly determined breed clusters obtained from $\mathrm{CN}$ states. Turopolje, the breed that accounted for the largest number of CNVs (with the largest fraction of the genome covered by CNVRs), was clustered apart, as also reported with SNP data (Muñoz et al. 2018a, 2018b; Muñoz et al. 2019; Bovo et al. in preparation).

Some CNVRs were considered as breed-specific or identified in a few breeds, suggesting that this variability might contribute to the determination of several phenotypic characteristics that distinguish autochthonous and commercial European breeds. In addition, considering the whole patterns of CNVRs that we detected, a quite high frequency of these events was classified as mixed CNVs (including both gains and losses). This indicates that, despite breeds sharing genome regions affected by $\mathrm{CNV}$, the single breed carries a gain or a loss specific to the breed itself.

In the current study, an average of 77 CNVRs $(\sim 16 \%$ of all breed reported CNVRs) were considered as private for each analysed breed, highlighting the power of the DNA pooling strategy in capturing distinctive breed features. However, as the sequencing depth is not high, for a given private CNVR we cannot completely exclude the possibility that some animals of the other investigated breeds could carry the same alleles in these regions. The remaining CNVRs were shared among two or more breeds, indicating that admixture and crossbreeding events or a common origin might have contributed to the spread of this variability. However, further studies are needed to clarify their allelic status or their common origin, as in our first survey we did not characterise in detail the precise breakdown positions and structure of all identified CNVRs.

The CNV regions we detected overlapped genes involved in different biological processes, including the nervous system and sensory perception such as olfactory signalling. Brain functions control various behaviours, including feeding, habitat selection, reproduction and social interaction, that strongly depend on the genetic architecture of an individual (Bendesky \& Bargmann 2011). Several studies in mammals, including pigs, have reported CNVs in genes involved in the olfactory signalling pathway, linking gene variability to food foraging and mate recognition abilities (Paudel et al. 2015; Keel et al. 2019). In addition, considering the overlapping of CNVRs and QTL regions, the main traits associated with changes in $\mathrm{CN}$ state were meat quality, body shape and conformation, reproduction and metabolism. Variability in chromosome regions harbouring functionally relevant genes or QTL may reflect the adaptation of these breeds to different production systems and environments.

The impact of this type of variability on the exterior characteristics of pigs has already been demonstrated for the CNVs in the KIT gene region affecting coat colours and patterns that characterise the Dominant white phenotype (Rubin et al. 2012). There was other evidence for the CNVs in the MS3B3 gene region, involved in ear size as mainly reported in Chinese breeds (Chen et al. 2018). These CNVRs were also detected in our study with some interesting new information for some of the analysed breeds.

The complexity of the Dominant white KIT locus has been explained by the presence of six main allele groups (in addition to a few other potential variants; Fontanesi \& Russo 2013): (i) a recessive wt allele $i$ (that is carried by wild boar and coloured pigs); (ii) the Patch allele $I^{P}$ (determining spotted patterns); (iii) the Belt allele $I^{\text {Be }}$ (determining the belted phenotype); (iv) the Roan/Gray allele $I^{R n}$ or $I^{d}$ (causing the grey-roan phenotype); (v) the dominant white alleles $I$, comprising several forms (e.g. $I^{1}$, $I^{2}$ and $I^{3}$ ) and causing the solid white phenotype that mainly characterises Large White and Landrace breeds; and (vi) the $I^{L}$ allele, a null and lethal allele (Johansson et al. 1996; Marklund et al. 1998; Johansson et al. 2005; Rubin et al. 2012). Variants in this chromosome region are mainly associated with a $450 \mathrm{kbp}$ duplication encompassing the entire KIT gene (DUP1; the only $\mathrm{CN}$ of the $I^{P}$ allele), including also another $4.3 \mathrm{kbp}$ duplication (DUP2) located approximately $100 \mathrm{kbp}$ upstream of KIT gene and a $23 \mathrm{kbp}$ duplication (DUP3) approximately $100 \mathrm{kbp}$ downstream from KIT, which in turn resulted in another $4.3 \mathrm{kbp}$ duplication (DUP4; Rubin et al. 2012). The $I$ alleles presented variable CNs of DUP1/2/3/4, whereas DUP2/3/ 4 were identified in pigs with the $I^{\text {Be }}$ allele (Rubin et al. 2012). Moreover, a recent whole-genome resequencing study uncovered new KIT alleles conferring different coat colour phenotypes (Wu et al. 2019). The CN states that we identified in our study encompassed all four duplicated regions, describing for the first time the structure of the KIT gene in several autochthonous pig breeds (Fig. 4a).

In addition, analysis of sequencing data allowed us to estimate the frequency of the splice mutation g.41486012G $>$ A (rs345599765) that distinguishes the $\mathrm{CN}$ state of the $I^{p}$ from the I Dominant white allele series (Marklund et al. 1998). As expected, all breeds that did not show any duplicated regions were characterised by solid 
coat colours and did not have the splice mutation. They are considered to carry only the $i$ wt at the Dominant white locus. The Sarda, which is a breed not fixed for any coat colours and that also includes white and white spotted pigs, showed the presence of DUP1, with some faint signs at the DUP4 position (with a low frequency of the splice mutation). Several alleles at the KIT gene might be present in this breed, including $I^{P}, I$ variants and $I^{B e}$ forms. A similar pattern was observed in the Lithuanian Indigenous Wattle breed, which includes mainly spotted pigs. According to the $\mathrm{CN}$ state observed in this breed, $I^{P}$ might be the most frequent allele, even if other $I^{B e}$ and $I$ forms (including also DUP4) might be present. A more marked $\mathrm{CN}$ pattern was evidenced for the Bísara breed (which has mainly heterogeneous coats: grey or black and white or spotted), for which a DUP1 CN status was reported similar to that of Sarda and Lithuanian Indigenous Wattle, in addition to DUP2-3 (without signals indicating the presence of DUP4).

Analysis of the KIT gene region in breeds characterised by a belted phenotype, even if not homogeneous, indicated that more alleles at this locus might produce belted pigs even if with some different phenotypic effects. Cinta Senese and Basque had equal CN state at DUP2-3 but differed in DUP4 (higher in Basque and lower in Cinta Senese). Cinta Senese is a classical belted breed whereas Basque pigs are usually black and white with heterogeneous patterns but usually with black head and rump. Other breeds having white belts of varying size and shape (Krškopolje and SchwäbischHällisches Schwein) showed only DUP2 and DUP4. The connection between the two breeds might be derived by ancestral origins (not clearly defined) that preserved the same structure at the Dominant white locus. $\mathrm{Wu}$ et al. (2019) observed that the presence of DUP2 together with DUP4 can produce a belted phenotype in Duroc $\times$ (Landrace $\times$ Large White) hybrid pigs. The presence of multiple alleles conferring a belted phenotype is also confirmed by the results of the analysis of the rs328592739 SNP in the KIT gene that was associated with the belted pattern in Cinta Senese pigs (Fontanesi et al. 2016) but not Krškopolje and Schwäbisch-Hällisches Schwein pigs (Ogorevc et al. 2017).

White breeds (Italian Large White and Lithuanian White Old Type) had a classical CN pattern in DUP1-4 and the splice mutation already described for completely white pigs carrying I alleles (Fontanesi et al. 2010a). Heterogeneity on the presence of the splice mutation suggested that Dominant white alleles have different G/A ratios at this position. In Lithuanian White Old Type, gene copies at this position carried G only in one out of five copies (as estimated from its 0.20 frequency). In Italian Large White, about two out of three gene copies carried the $G$ nucleotide $(G=0.68)$, suggesting that the $\mathrm{CNV}$ structure in this breed might be determined by different Dominant white alleles than those frequently present in the Lithuanian White Old Type breed.
Interesting $\mathrm{CN}$ patterns were also observed in the region of SSC5 encompassing the last exons of the MSRB3 gene (Fig. 4b), which is associated with ear size (Chen et al. 2018). These authors proposed that large ear size is due to the increased $\mathrm{CN}$ state in this region, which affects the expression of the nearby miR-584-5p that in turn inhibits the expression of its target gene MSRB3. Our CNV analysis for the MSRB3 gene across autochthonous European pig breeds indicated, with the exception of some breeds, a significant correlation between ear size and the average $\mathrm{CN}$ state (Fig. 4c). The latter also correlated with allele frequencies estimated for the rs340841870 and rs326411202 SNPs (outside this CNVR), which suggested the presence of linkage between these two types of variants: allele $\mathrm{C}$ at both positions is associated with a normal copy state whereas the alternative allele at both sides $(\mathrm{T})$ is associated with the presence of five or six copies (of the linked multiple copy region), as estimated from the sequencing data in the CNVR. Even if pigs of the studied breeds were in general described as having breed-specific traits, heterogeneity for ear size has already been reported in some breeds which might not actually have fixed ear size and shape (Schiavo et al. 2019). Therefore, correlation between $\mathrm{CN}$ state and ear size might not be precisely estimated by the DNA pooling approach (Fig. 4b). It is also worth mentioning that ear size and position have already been shown to be under polygenic control with a few major genes affecting these traits (e.g. Wei et al. 2007; Ma et al. 2009; Ren et al. 2011). Thus, other genomic regions and polymorphisms could be responsible for the ear size phenotype in some of the analysed breeds.

The CNV in the ELOVL6 gene might be interesting to explain economically relevant traits, considering the role of this gene in affecting fatty acid composition in pigs (Corominas et al. 2013). Other studies have reported that variability in this gene or variability in its expression level might explain, at least in part, differences in intramuscular fat accumulation and lipid metabolism among breeds, which are relevant for meat quality, considering also genotype-feeding interactions to design appropriate fatty acid diets in pigs to maximise this aspect (e.g. Benítez et al. 2016; Revilla et al. 2018; Muñoz et al. 2018). Association studies and functional analysis of the CNV in this gene are needed to understand if this variability could affect meat quality traits in pigs. Targeted analyses are also needed to detect with more precision if this variability segregates within the analysed breeds as well as in other breeds in which meat quality parameters are important factors determining the quality of their products.

Detailed analyses of the $\mathrm{CN}$ states of some chromosome regions can also identify (or suppose) the occurrence of other or more complex mutational events that might not be properly considered as derived by CNVs. The case of the ZNF622 gene that reported three distinct $\mathrm{CN}$ gains (mainly in the correspondence of exonic regions) might raise a few 
hypotheses on the occurrence of this strange pattern. The three divided $\mathrm{CN}$ gains might be due to the presence of a pseudogene derived by the ZNF622 gene (inserted somewhere into the genome) or that the duplication of the gene subsequently underwent other mutational events that eliminated most of the sequence of introns 3 and 4 (Fig. 5b). Other studies are needed to clarify these hypotheses. After a preliminary analysis, $\mathrm{CN}$ states reported in the correspondence of this gene appeared to produce a private condition in the Turopolje breed that did not have any $\mathrm{CN}$ gain (common in all other breeds). Inspection of the clustering analysis for the $\mathrm{CN}$ at this gene in all breeds indicated that two other breeds (Krškopolje and Italian Duroc) might not have fixed $\mathrm{CN}$ gains, mainly in the correspondence of the annotated exons of the ZNF622 gene.

On the whole, our survey on European pig breeds reported that CNVRs occupy $26.1 \mathrm{Mbp}$, representing $1.15 \%$ of the reference genome size. Compared with other whole-genome sequencing-based studies, this genome fraction is similar to what was reported by Paudel et al. (2015) and Keel et al. (2019) (17.83 and 22.9 Mbp respectively). Two other studies (Paudel et al. 2013; Jiang et al. 2014) identified larger fractions of the pig genome covered by CNVRs (39.2 and 102.8 Mbp respectively). Although this divergence could be attributed in part to the algorithms used to detect CNVs and the sequencing approaches (single pigs vs. pools of individuals), it might also be due to differences among the studied pig populations. Distribution of CNVR sizes showed a decrease in CNVR counts while increasing their size, as also described by Jiang et al. (2014). Differences among breeds were also clearly shown in our study, as detailed above. Some of the CNVRs we detected in our study overlapped with CNV events reported by the other whole-genome sequencing studies (on average, $13 \%$ of overlap), pointing out that they could also exist in other breeds that we did not survey. However, they represent just a small fraction, strengthening the evidence that CNVs are breed-specific genome features. Additional studies are needed to obtain a global overview of CNVs segregating in the S. scrofa species, by comparing more breeds and populations.

As CNVs mutate about two to three times faster than SNPs, some of the CNVRs that we detected across several breeds could eventually also be derived from recurrent mutational events through non-allelic homologous recombination, potentially driven by the presence of repeated regions within or in flanking positions (Liu et al. 2012). Analyses of CNVRs and their flanking regions identified enrichments of different classes of repeated elements, confirming what other studies reported in this species (e.g. Paudel et al. 2013; Wang et al. 2015a). This further suggests that these sequence features might contribute to chromosome instability and mutational mechanisms also promoting these structural changes in S. scrofa.
Our study investigated CNVs in the porcine genome over a large number of pig breeds that represent important European genetic resources for this species. This variability can explain part of the genetic diversity among breeds and might contribute to explanation of their origin, history and adaptation to a variety of production systems. Further studies are needed to better understand how CNVs could be considered in defining conservation programmes for these autochthonous genetic resources.

\section{Acknowledgements}

S.B. received a fellowship from the Europe-FAANG COST Action. This work received funding from the University of Bologna RFO 2016-2019 programme, the Italian MIUR 2017 PigPhenomics project, the Slovenian Agency of Research (grant P4-0133) and the European Union's Horizon 2020 research and innovation programme under grant agreement no. 634476 for the project with acronym TREASURE. The content of this article reflects only the authors' view and the European Union Agency is not responsible for any use that may be made of the information it contains.

\section{Conflict of interests}

The authors declare they do not have any competing interests.

\section{Data availability}

Sequence data generated and analysed in the current study are available in the EMBL-EBI European Nucleotide Archive repository (http://www.ebi.ac.uk/ena), under the study accession no. PRJEB36830. CNVRs are available as Table S4 and from the corresponding author on reasonable request.

\section{References}

Alkan C., Coe B.P. \& Eichler E.E. (2011) Genome structural variation discovery and genotyping. Nature Reviews Genetics 12 , 363-76.

Andersen I.L., Nævdal E. \& Bøe K.E. (2011) Maternal investment, sibling competition, and offspring survival with increasing litter size and parity in pigs (Sus scrofa). Behavioral Ecology and Sociobiology 65, 1159-67.

Bendesky A. \& Bargmann C.I. (2011) Genetic contributions to behavioural diversity at the gene-environment interface. Nature Reviews Genetics 12, 809-20.

Benítez R., Núñez Y., Fernández A., Isabel B., Rodríguez C., Daza A., López-Bote C., Silió L. \& Óvilo C. (2016) Adipose tissue transcriptional response of lipid metabolism genes in growing Iberian pigs fed oleic acid v. carbohydrate enriched diets. Animal 10, 939-46. 
Bickhart D.M. \& Liu G.E. (2014) The challenges and importance of structural variation detection in livestock. Frontiers in Genetics $5,37$.

Bickhart D.M., Hou Y., Schroeder S.G. et al. (2012) Copy number variation of individual cattle genomes using next-generation sequencing. Genome Research 22, 778-90.

Čandek-Potokar M. \& Nieto Liñan R.M. (2019) European Local Pig Breeds - Diversity and Performance. A study of project TREASURE. IntechOpen, London.

Chen C., Qiao R., Wei R., Guo Y., Ai H., Ma J., Ren J. \& Huang L. (2012) A comprehensive survey of copy number variation in 18 diverse pig populations and identification of candidate copy number variable genes associated with complex traits. BMC Genomics 13, 733.

Chen C., Liu C., Xiong X., Fang S., Yang H., Zhang Z., Ren J., Guo Y. \& Huang L. (2018) Copy number variation in the MSRB3 gene enlarges porcine ear size through a mechanism involving miR584-5p. Genetics Selection Evolution 50, 72.

Corominas J., Ramayo-Caldas Y., Puig-Oliveras A., Pérez-Montarelo D., Noguera J.L., Folch J.M. \& Ballester M. (2013) Polymorphism in the ELOVL6 gene is associated with a major QTL effect on fatty acid composition in pigs. PLoS ONE 8, e53687.

Dong K., Pu Y., Yao N., Shu G., Liu X., He X., Zhao Q., Guan W. \& Ma Y. (2015) Copy number variation detection using SNP genotyping arrays in three Chinese pig breeds. Animal Genetics $46,101-9$.

Fadista J., Nygaard M., Holm L.E., Thomsen B. \& Bendixen C. (2008) A snapshot of CNVs in the pig genome. PLoS ONE 3, e3916.

Fadista J., Thomsen B., Holm L.-E. \& Bendixen C. (2010) Copy number variation in the bovine genome. BMC Genomics 11, 284.

Fernández A.I., Barragán C., Fernández A., Rodríguez M.C. \& Villanueva B. (2014) Copy number variants in a highly inbred Iberian porcine strain. Animal Genetics 45, 357-66.

Feuk L., Carson A.R. \& Scherer S.W. (2006) Structural variation in the human genome. Nature Reviews Genetics 7, 85-97.

Fontanesi L. \& Russo V. (2013) Molecular genetics of coat colour in pigs. Acta Agriculturae Slovenica 4, 16.

Fontanesi L., D’Alessandro E., Scotti E., Liotta L., Crovetti A., Chiofalo V. \& Russo V. (2010a) Genetic heterogeneity and selection signature at the KIT gene in pigs showing different coat colours and patterns. Animal Genetics 41, 478-92.

Fontanesi L., Martelli P.L., Beretti F., Riggio V., Dall'Olio S., Colombo M., Casadio R., Russo V. \& Portolano B. (2010b) An initial comparative map of copy number variations in the goat (Capra hircus) genome. BMC Genomics 11, 639.

Fontanesi L., Beretti F., Martelli P.L., Colombo M., Dall'olio S., Occidente M., Portolano B., Casadio R., Matassino D. \& Russo V. (2011) A first comparative map of copy number variations in the sheep genome. Genomics 97, 158-65.

Fontanesi L., Martelli P.L., Scotti E., Russo V., Rogel-Gaillard C., Casadio R. \& Vernesi C. (2012) Exploring copy number variation in the rabbit (Oryctolagus cuniculus) genome by array comparative genome hybridization. Genomics 100, 245-51.

Fontanesi L., Scotti E., Gallo M., Nanni Costa L. \& Dall'Olio S. (2016) Authentication of "mono-breed" pork products: identification of a coat colour gene marker in Cinta Senese pigs useful to this purpose. Livestock Science 184, 71-7.

Fowler K.E., Pong-Wong R., Bauer J., Clemente E.J., Reitter C.P., Affara N.A., Waite S., Walling G.A. \& Griffin D.K. (2013) Genome wide analysis reveals single nucleotide polymorphisms associated with fatness and putative novel copy number variants in three pig breeds. BMC Genomics 14, 784.

Hasegawa Y., Taylor D., Ovchinnikov D.A., Wolvetang E.J., de Torrenté L. \& Mar J.C. (2015) Variability of gene expression identifies transcriptional regulators of early human embryonic development. PLoS Genetics 11, e1005428.

Hu Z.L., Park C.A. \& Reecy J.M. (2019) Building a livestock genetic and genomic information knowledgebase through integrative developments of animal QTLdb and CorrDB. Nucleic Acids Research 47, D701-10.

Jiang J., Wang J., Wang H. et al. (2014) Global copy number analyses by next generation sequencing provide insight into pig genome variation. BMC Genomics 15, 593.

Johansson M.M., Chaudhary R., Hellmén E., Höyheim B., Chowdhary B. \& Andersson L. (1996) Pigs with the dominant white coat color phenotype carry a duplication of the KIT gene encoding the mast/stem cell growth factor receptor. Mammalian Genome 7, 822-30.

Johansson A., Pielberg G., Andersson L. \& Edfors-Lilja I. (2005) Polymorphism at the porcine dominant white/KIT locus influence coat colour and peripheral blood cell measures. Animal Genetics 36, 288-96.

Keel B.N., Nonneman D.J., Lindholm-Perry A.K., Oliver W.T. \& Rohrer G.A. (2019) A Survey of Copy Number Variation in the Porcine Genome Detected From Whole-Genome Sequence. Frontiers in Genetics 10. https://doi.org/10.3389/fgene.2019. 00737

Klambauer G., Schwarzbauer K., Mayr A., Clevert D.A., Mitterecker A., Bodenhofer U. \& Hochreiter S. (2012) cn.MOPS: mixture of Poissons for discovering copy number variations in next-generation sequencing data with a low false discovery rate. Nucleic Acids Research 40, e69.

Li H. \& Durbin R. (2009) Fast and accurate short read alignment with Burrows-Wheeler transform. Bioinformatics 25, 1754 60.

Li Y., Mei S., Zhang X., Peng X., Liu G., Tao H., Wu H., Jiang S., Xiong Y. \& Li F. (2012) Identification of genome-wide copy number variations among diverse pig breeds by array CGH. BMC Genomics 13, 725.

Liu P., Carvalho C.M.B., Hastings P.J. \& Lupski J.R. (2012) Mechanisms for recurrent and complex human genomic rearrangements. Current Opinion in Genetics \& Development 22, 211-20.

Liu M., Zhou Y., Rosen B.D. et al. (2019) Diversity of copy number variation in the worldwide goat population. Heredity 122, 63646.

Long Y., Su Y., Ai H. et al. (2016) A genome-wide association study of copy number variations with umbilical hernia in swine. Animal Genetics 47, 298-305.

Ma J., Qi W., Ren D. et al. (2009) A genome scan for quantitative trait loci affecting three ear traits in a White Duroc $\times$ Chinese Erhualian resource population. Animal Genetics 40, 463-7.

Marklund S., Kijas J., Rodriguez-Martinez H., Rönnstrand L., Funa K., Moller M., Lange D., Edfors-Lilja I. \& Andersson L. (1998) Molecular basis for the dominant white phenotype in the domestic pig. Genome Research 8, 826-33.

Mi H., Muruganujan A., Ebert D., Huang X. \& Thomas P.D. (2019) PANTHER version 14: more genomes, a new PANTHER GO-slim 
and improvements in enrichment analysis tools. Nucleic Acids Research 47, D419-26.

Molnár J., Nagy T., Stéger V., Tóth G., Marincs F. \& Barta E. (2014) Genome sequencing and analysis of Mangalica, a fatty local pig of Hungary. BMC Genomics 15, 761.

Muñoz M., Bozzi R., García F. et al. (2018a) Diversity across major and candidate genes in European local pig breeds. PLoS ONE 13 , e0207475.

Muñoz M., García-Casco J.M., Caraballo C., Fernández-Barroso M.Á., Sánchez-Esquiliche F., Gómez F., Rodríguez M.D.C. \& Silió L. (2018b) Identification of candidate genes and regulatory factors underlying intramuscular fat content through longissimus dorsi transcriptome analyses in heavy Iberian pigs. Frontiers in Genetics 9, 608.

Muñoz M., Bozzi R., García-Casco J. et al. (2019) Genomic diversity, linkage disequilibrium and selection signatures in European local pig breeds assessed with a high density SNP chip. Scientific Reports 9, 13546.

Ogorevc J., Zorc M., Škrlep M., Bozzi R., Petig M., Fontanesi L., Čandek-Potokar M. \& Dovč P. (2017) Is KIT locus polymorphism rs328592739 related to white belt phenotype in Krškopolje pig? Agriculturae Conspectus Scientificus 82, 155-61.

Ovilo C., Clop A., Noguera J.L. et al. (2002) Quantitative trait locus mapping for meat quality traits in an Iberian $\times$ Landrace F2 pig population. Journal of Animal Science 80, 2801-8.

Paudel Y., Madsen O., Megens H.J., Frantz L.A.F., Bosse M., Bastiaansen J.W.M., Crooijmans R.P.M.A. \& Groenen M.A.M. (2013) Evolutionary dynamics of copy number variation in pig genomes in the context of adaptation and domestication. BMC Genomics 14, 449.

Paudel Y., Madsen O., Megens H.J., Frantz L.A.F., Bosse M., Crooijmans R.P.M.A. \& Groenen M.A.M. (2015) Copy number variation in the speciation of pigs: a possible prominent role for olfactory receptors. BMC Genomics 16, 330.

Pirooznia M., Goes F.S. \& Zandi P.P. (2015) Whole-genome CNV analysis: advances in computational approaches. Frontiers in Genetics 6, 138.

Pollard M.O., Gurdasani D., Mentzer A.J., Porter T. \& Sandhu M.S. (2018) Long reads: their purpose and place. Human Molecular Genetics 27, R234-41.

Quinlan A.R. \& Hall I.M. (2010) BEDTools: a flexible suite of utilities for comparing genomic features. Bioinformatics 26, 841-2.

Ramayo-Caldas Y., Castelló A., Pena R.N., Alves E., Mercadé A., Souza C.A., Fernández A.I., Perez-Enciso M. \& Folch J.M. (2010) Copy number variation in the porcine genome inferred from a 60 k SNP BeadChip. BMC Genomics 11, 593.

R Core Team (2018) R: A Language and Environment for Statistical Computing. R Foundation for Statistical Computing, Vienna.

Redon R., Ishikawa S., Fitch K.R. et al. (2006) Global variation in copy number in the human genome. Nature 444, 444-54.

Ren J., Duan Y., Qiao R. et al. (2011) A missense mutation in PPARD causes a major QTL effect on ear size in pigs. PLoS Genetics 7, e1002043.

Revay T., Quach A.T., Maignel L., Sullivan B. \& King W.A. (2015) Copy number variations in high and low fertility breeding boars. BMC Genomics 16, 280.

Revilla M., Puig-Oliveras A., Castelló A., Crespo-Piazuelo D., Paludo E., Fernández A.I., Ballester M. \& Folch J.M. (2017) A global analysis of CNVs in swine using whole genome sequence data and association analysis with fatty acid composition and growth traits. PLOS ONE 12, e0177014.

Revilla M., Puig-Oliveras A., Crespo-Piazuelo D., Criado-Mesas L., Castelló A., Fernández A.I., Ballester M. \& Folch J.M. (2018) Expression analysis of candidate genes for fatty acid composition in adipose tissue and identification of regulatory regions. Scientific Reports 8, 2045.

Ribani A., Utzeri V.J., Geraci C., et al. (2019) Signatures of dedomestication in autochthonous pig breeds and of domestication in wild boar populations from MC1R and NR6A1 allele distribution. Animal Genetics 50, 166-71.

Rubin C.J., Megens H.J., Martinez B.A. et al. (2012) Strong signatures of selection in the domestic pig genome. Proceedings of the National Academy of Sciences of the United States of America 109, 19529-36.

Sambrook J., Fritsch E.F. \& Maniatis T. (1989) Molecular Cloning: A Laboratory Manual, 2nd edn. Cold Spring Harbor Laboratory Press, Cold Spring Harbor.

Schiavo G., Dolezal M.A., Scotti E., Bertolini F., Calò D.G., Galimberti G., Russo V. \& Fontanesi L. (2014) Copy number variants in Italian Large White pigs detected using high-density single nucleotide polymorphisms and their association with back fat thickness. Animal Genetics 45, 745-9.

Schiavo G., Bertolini F., Utzeri V.J., Ribani A., Geraci C., Santoro L., Óvilo C., Fernández A.I., Gallo M. \& Fontanesi L. (2018) Taking advantage from phenotype variability in a local animal genetic resource: identification of genomic regions associated with the hairless phenotype in Casertana pigs. Animal Genetics 49, 321-5.

Schiavo G., Bovo S., Tinarelli S., Bertolini F., Dall'Olio S., Gallo M. \& Fontanesi L. (2019) Genome-wide association analyses for several exterior traits in the autochthonous Casertana pig breed. Livestock Science 230, 103842.

Schiavo G., Bertolini F., Galimberti G., Bovo S., Dall'Olio S., Nanni Costa L., Gallo M. \& Fontanesi L. (2020a) A machine learning approach for the identification of population-informative markers from high-throughput genotyping data: application to several pig breeds. Animal 14, 223-32.

Schiavo G., Bovo S., Bertolini F., Tinarelli S., Dall'Olio S., Nanni Costa L., Gallo M. \& Fontanesi L. (2020b) Comparative evaluation of genomic inbreeding parameters in seven commercial and autochthonous pig breeds. Animal 14, 910-20.

Silió L., Barragán C., Fernández A.I., García-Casco J. \& Rodríguez M.C. (2016) Assessing effective population size, coancestry and inbreeding effects on litter size using the pedigree and SNP data in closed lines of the Iberian pig breed. Journal of Animal Breeding and Genetics 133, 145-54.

Stafuzza N.B., Silva R.M.O., Fragomeni B.O., Masuda Y., Huang Y., Gray K. \& Lourenco D.A.L. (2019) A genome-wide single nucleotide polymorphism and copy number variation analysis for number of piglets born alive. BMC Genomics 20, 321.

Tomás A., Ramírez O., Casellas J. et al. (2011) Quantitative trait loci for fatness at growing and reproductive stages in Iberian $\times$ Meishan F(2) sows. Animal Genetics 42, 548-51.

Wang J., Jiang J., Fu W., Jiang L., Ding X., Liu J.F. \& Zhang Q. (2012) A genome-wide detection of copy number variations using SNP genotyping arrays in swine. BMC Genomics 13, 273.

Wang J., Jiang J., Wang H., Kang H., Zhang Q. \& Liu J.-F. (2014) Enhancing genome-wide copy number variation identification by 
high density array CGH using diverse resources of pig breeds. PLOS ONE 9, e87571.

Wang H., Wang C., Yang K., Liu J., Zhang Y., Wang Y., Xu X., Michal J.J., Jiang Z. \& Liu B. (2015a) Genome wide distributions and functional characterization of copy number variations between Chinese and Western pigs. PLOS ONE 10, e0131522.

Wang J., Jiang J., Wang H., Kang H., Zhang Q. \& Liu J.-F. (2015b) Improved detection and characterization of copy number variations among diverse pig breeds by array CGH. G3: Genes, Genomes, Genetics 5, 1253-61.

Wang L., Xu L., Liu X. et al. (2015c) Copy number variation-based genome wide association study reveals additional variants contributing to meat quality in Swine. Scientific Reports 5, 12535.

Wang Y., Zhang T. \& Wang C. (2019a) Detection and analysis of genome-wide copy number variation in the pig genome using an $80 \mathrm{~K}$ SNP Beadchip. Journal of Animal Breeding and Genetics 137, 166-76.

Wang Z., Sun H., Chen Q., Zhang X., Wang Q. \& Pan Y. (2019b) A genome scan for selection signatures in Taihu pig breeds using next-generation sequencing. Animal 13, 683-93.

Wei W.H., de Koning D.J., Penman J.C., Finlayson H.A., Archibald A.L. \& Haley C.S. (2007) QTL modulating ear size and erectness in pigs. Animal Genetics 38, 222-6.

Wiedmann R.T., Nonneman D.J. \& Rohrer G.A. (2015) Genomewide copy number variations using SNP genotyping in a mixed breed swine population. PLoS ONE 10, e0133529.

Wilkinson S., Lu Z.H., Megens H.J., Archibald A.L., Haley C., Jackson I.J., Groenen M.A.M., Crooijmans R.P.M.A., Ogden R. \& Wiener P. (2013) Signatures of diversifying selection in European pig breeds. PLoS Genetics 9, e1003453.

Winchester L., Yau C. \& Ragoussis J. (2009) Comparing CNV detection methods for SNP arrays. Briefings in Functional Genomics \& Proteomics 8, 353-66.

Wu Z., Deng Z., Huang M., Hou Y., Zhang H., Chen H. \& Ren J. (2019) Whole-genome resequencing identifies KIT new alleles that affect coat color phenotypes in pigs. Frontiers in Genetics 10, 218.

Xie J., Li R., Li S., Ran X., Wang J., Jiang J. \& Zhao P. (2016) Identification of copy number variations in Xiang and Kele pigs. PLOS ONE 11, e0148565.

Yang B., Cui L., Perez-Enciso M. et al. (2017) Genome-wide SNP data unveils the globalization of domesticated pigs. Genetics Selection Evolution 49, 71.
Yang L., Xu L., Zhou Y., Liu M., Wang L., Kijas J.W., Zhang H., Li L. \& Liu G.E. (2018) Diversity of copy number variation in a worldwide population of sheep. Genomics 110, 143-8.

Yi G., Qu L., Liu J., Yan Y., Xu G. \& Yang N. (2014) Genome-wide patterns of copy number variation in the diversified chicken genomes using next-generation sequencing. BMC Genomics 15, 962.

Zhang F., Gu W., Hurles M.E. \& Lupski J.R. (2009) Copy number variation in human health, disease, and evolution. Annual Review of Genomics and Human Genetics 10, 451-81.

Zhang Y., Liang J., Zhang L. et al. (2015) Porcine methionine sulfoxide reductase B3: molecular cloning, tissue-specific expression profiles, and polymorphisms associated with ear size in Sus scrofa. Journal of Animal Science and Biotechnology 6, 60.

\section{Supporting information}

Additional supporting information may be found online in the Supporting Information section at the end of the article.

Table S1 Details of the analysed animals and investigated breeds, including geographical distribution and phenotypic description

Table S2 Summary statistics of whole-genome sequencing

Table S3 Summary statistics of detected CNVs, stratified by chromosome

Table S4 CNVRs detected over all analysed breeds

Table S5 Summary statistics of detected CNVRs, stratified by pig breed

Table S6 Over-represented repeated element classes

Table S7 Over-represented QTL

Table S8 Within-CNVR over-represented biological functions

Table S9 Allele frequency of the SNPs at the KIT and MSRB3 genes estimated from sequencing data

Table S10 Summary statistics of CNVRs previously identified 